\title{
O gênero Phymatidium (Orchidaceae: Oncidiinae) no estado do Paraná
}

\author{
The genus Phymatidium (Orchidaceae: Oncidiinae) in the state of Paraná
}

Carla Adriane Royer ${ }^{1,3}$, Antonio Luiz Vieira Toscano de Brito ${ }^{2}$ \& Eric de Camargo Smidt ${ }^{1}$

\begin{abstract}
Resumo
A partir de consultas a herbários nacionais e estrangeiros, cinco espécies e duas variedades de Phymatidium Lindl. foram encontradas no Paraná: Phymatidium aquinoi, P. delicatulum, P. delicatulum var. curvisepalum, P. falcifolium, P. hysteranthum, P. microphyllum e P. microphyllum var. herteri. O gênero é registrado em 35 dos 399 municípios paranaenses, principalmente na Floresta Ombrófila Densa e Floresta Ombrófila Mista, localizadas na Serra do Mar, Primeiro e Segundo Planaltos. Segundo os critérios da IUCN, a maioria dos táxons encontra-se classificada na categoria vulnerável para o estado. Phymatidium delicatulum é a espécie mais comum, com ampla distribuição, e $P$. hysteranthum a espécie mais restrita, registrada pela primeira vez no estado. Chave de identificação dos táxons, descrições, ilustrações, dados sobre distribuição geográfica e conservação, além de uma lista de materiais representativos, são apresentados.
\end{abstract}

Palavras-chave: biodiversidade, flora do Paraná, Mata Atlântica, IUCN.

\begin{abstract}
Based on the study of material in Brazilian and foreign herbaria, five species and two varieties of Phymatidium are recognized for Paraná state: Phymatidium aquinoi, $P$. delicatulum, $P$. delicatulum var. curvisepalum, $P$. falcifolium, $P$. hysteranthum, $P$. microphyllum and $P$. microphyllum var. herteri. The genus is recorded in 35 of the 399 municipalities of the state, mostly inhabiting Floresta Ombrófila Densa and Floresta Ombrófila Mista vegetation, situated in the Serra do Mar, Primeiro and Segundo Planaltos. Following IUCN criteria, most taxa are classified here as vulnerable in the state. Phymatidium delicatulum is the commonest species, with the widest distribution, and P. hysteranthum, with the narrowest distribution, is recorded for the first time in Paraná. An identification key for species and varieties, descriptions, illustrations, data on distribution and conservation, and a list of representative material are provided herewith.
\end{abstract}

Key words: biodiversity, flora of Paraná, Mata Atlântica, IUCN.

\section{Introdução}

Orchidaceae Juss. é uma família de monocotiledôneas pertencente à ordem Asparagales Bromhead (APG III 2009). Trata-se de uma das maiores famílias dentre as Angiospermas, com 24.500 espécies e distribuição cosmopolita (Dressler 2005). Cinco subfamílias são reconhecidas: Apostasioideae Garay, Vanilloideae Szlach., Cypripedioideae Garay, Orchidoideae Lindl. e Epidendroideae Lindl. (Chase et al. 2003). De acordo com Barros et al. (2013), existem no Brasil cerca de 236 gêneros e 2440 espécies de orquídeas. No estado do Paraná, Orchidaceae é a família mais diversa dentre as monocotiledôneas com cerca de 127 gêneros e 588 espécies (Barros et al. 2013).
O gênero Phymatidium Lindl. pertence ao grupo Ornithocephalus da subtribo Oncidiinae Benth., subfamília Epidendroideae. Foi estabelecido por Lindley em 1833, baseado em duas espécies, $P$. falcifolium Lindl. e $P$. delicatulum Lindl., este último selecionado como lectótipo do gênero por Toscano de Brito (2001).

Phymatidium consiste de 11 táxons restritos principalmente à Região Sudeste do Brasil (Toscano de Brito 2007, Toscano de Brito em prep.), com ocorrência registrada de $P$. delicatulum também para a Argentina (Johnson 2001) e $P$. falcifolium para o Uruguai (Herter 1930).

Ao descrever $P$. tillandsiodes $(=P$. falcifolium $)$ Barbosa Rodrigues (1882) registrou pela primeira

\footnotetext{
${ }^{1}$ Universidade Federal do Paraná, Setor de Ciências Biológicas, Centro Politécnico, Jardim da Américas, 81531-980, C.P. 19031, Curitiba, PR, Brasil.

${ }^{2}$ Marie Selby Botanical Gardens, 811 South Palm Avenue, Sarasota, FL 34236, USA.

${ }^{3}$ Autor para correspondência: carladriane@gmail.com
} 
vez uma espécie de Phymatidium para o Paraná, posteriornente também citado por Cogniaux (19041906). Pabst \& Dungs (1977) listaram dez espécies de Phymatidium para o Paraná, mas alguns desses táxons são atualmente considerados sinônimos enquanto outros tratados como sinônimos são agora reconhecidos como espécies ou variedades aceitas. Na recente revisão taxonômica do gênero (Toscano de Brito 2007), quatro espécies e duas variedades foram relatadas e documentadas como presentes em território paranaense. Essas mesmas espécies são também citadas por Barros et al. (2013).

Este trabalho tem como objetivo elaborar a monografia do gênero Phymatidium para o estado do Paraná, incluindo descrições, chave de identificação, ilustrações, estado de conservação e comentários sobre as espécies.

\section{Material e Métodos}

Análises morfológicas foram feitas de exsicatas obtidas dos herbários AMES, BHCB, C, F, FUEL, FURB, HB, HCF, HUCP, HUEFS, HUPG, ICN, K, MBM, MBML, MO, NY, PACA, R, S, SP, SPF e UPCB (acrônimos segundo Thiers (continuously updated)), e complementadas com materiais coletados em campo. A terminologia morfológica adotada foi baseada em Harris \& Harris (1994), Stern (2004) e Gonçalves \& Lorenzi (2011). A abreviação dos autores de cada táxon está de acordo com Brummitt \& Powell (1992). Para a padronização das descrições foi utilizado o programa DELTA (Dallwitz et al. 2011). Os sinônimos aceitos neste trabalho estão de acordo com a revisão taxonômica de Toscano de Brito (2007). A distribuição geográfica dos táxons no estado do Paraná foi mapeada em imagem delimitada por quadrículas de $1^{\circ} \times 1^{\circ}$ através do programa DIVA-GIS 7.5 (Hijmans et al. 2012). O estado de conservação de cada táxon foi inferido seguindo as recomendações do sistema IUCN (2010) levando em consideração o número de localidades, área, extensão e qualidade do habitat, sendo também examinada a Lista Vermelha de Plantas Ameaçadas de Extinção no Estado do Paraná (Hatschbach \& Ziller 1995).

A descrição dos habitats ocupados pelas espécies foi baseada nas cinco regiões ou zonas de paisagens naturais reconhecidas para o estado por Maack (1968): Litoral, Serra do Mar, Primeiro, Segundo e Terceiro Planaltos. Nestas são encontrados cinco tipos de vegetação (Veloso et al. 1991): 1. Floresta Ombrófila Densa, no litoral e Serra do Mar, com os subtipos de floresta Altomontana (acima de $1.000 \mathrm{~m}$ ), Montana (400$1.000 \mathrm{~m})$, Submontana $(30-400 \mathrm{~m})$ e de Terras Baixas (até $30 \mathrm{~m}$ ), além de formações associadas (refúgios ou campos de altitude, formações pioneiras ou restinga e mangue); 2. Floresta Ombrófila Mista, nas regiões mais altas ao sul da região planaltina; 3. Estepe Ombrófila (Campos Gerais) nas mesmas regiões; 4. Floresta Estacional Semidecidual Subxérica (norte e oeste do Segundo e Terceiro Planaltos); 5. Savana Estacional Subxérica (Cerrado), no nordeste do estado.

\section{Resultados e Discussão}

Phymatidium Lindl., Gen. Sp. Orchid. Pl.: 209. 1833.

Plantas epífitas, monopodiais. Raízes glabras ou papilosas. Rizoma ausente. Caule inconspícuo, raramente alongado, coberto pela bainha das folhas. Pseudobulbo ausente. Folhas espiraladas, sem pecíolo, não-articuladas, unifaciais, ensiformes a linear-subuladas, torcidas, cilíndricas, semicilíndricas ou subtríquetras em corte transversal, raramente bifaciais e dorsiventrais, verde-pálidas, base brevemente invaginante e decurrente, ápice agudo ou acuminado. Inflorescência axilar, racemosa, pauci a multiflora, escapo glabro ou papiloso; brácteas subuladas, glabras. Flores ressupinadas ou não, as sépalas, pétalas, labelo e coluna brancos, pedicelo glabro ou papiloso, ovário angular ou 3-carenado. Sépalas livres, ápice agudo a obtuso, a dorsal em geral levemente côncava, as laterais comumente falcadas e oblíquas, eretas, patentes ou reflexas, margens inteiras. Pétalas semelhantes às sépalas, usualmente suboblíquas; margens inteiras. Labelo séssil ou largo-unguiculado, inteiro ou levemente trilobado, agudo a obtuso; disco provido de calo geralmente verde, raro quase totalmente branco, carnoso, côncavo, glandular; margens inteiras, erosas ou denticuladas. Coluna usualmente sigmóide, ventralmente sulcada, ápice geralmente auriculado; rostelo inteiro, muito curto ou conspícuo; cavidade estigmática pequena, basal, raro conspícua; base da coluna estendida em tabula infraestigmática verde, raro quase totalmente branca, intumescida e carnosa, raramente ausente; antera terminal prolongada em bico curto ou longo; polínias 4, em pares superpostos, desiguais, mais ou menos ovoides, estipe caudado, espatulado ou cuneado; viscídio ovado a elíptico. Fruto pedicelado, subgloboso, carenado. 
Foram analisadas 155 exsicatas coletadas em 35 municípios do estado, todos pertencentes ao Bioma Mata Atlântica. Cinco espécies e duas variedades foram registradas no Paraná: Phymatidium aquinoi Schltr., P. delicatulum Lindl., P. delicatulum var. curvisepalum Toscano, P. falcifolium Lindl., P. hysteranthum Barb. Rodr., P. microphyllum (Barb. Rodr.) Toscano e P. microphyllum var. herteri (Schltr.) Toscano. Segundo Barros et al. (2013) o estado do Rio de Janeiro é o estado mais rico com registro de sete táxons, seguido do Paraná e São Paulo com seis. Com o presente o estado do Paraná passa, junto com o estado do Rio de Janeiro, a conter o maior numero de táxons do gênero.

Por ser um gênero restrito à Mata Atlântica, historicamente seus táxons encontram-se constantemente ameaçados. Na lista vermelha de plantas ameaçadas de extinção no estado do Paraná (Hatschbach \& Ziller 1995), nenhuma espécie ou variedade do gênero foi relatada como rara, em perigo ou vulnerável. Porém o presente estudo identificou espécies com poucos registros, fato que as enquadra nas categorias em perigo e criticamente em perigo, segundo os índices da IUCN (2010).

\section{Chave de identificação para os táxons de Phymatidium ocorrentes no estado do Paraná}

1. Folhas bifaciais, conduplicadas 4. Phymatidium falcifolium

1'. Folhas unifaciais, cilíndricas, semi-cilíndricas ou subtríquetras em corte transversal.

2. Coluna desprovida de tabula infraestigmática

2'. Coluna provida de tabula infraestigmática. 1. Phymatidium aquinoi

3. Aurículas da coluna glabras ou apenas obscuramente papilosas.

4. Sépalas laterais reflexas; antera prolongada em bico longo pelo menos três vezes mais longo do que a maior largura da antera 5. Phymatidium hysteranthum

4'. Sépalas laterais patentes ou eretas; antera prolongada em bico curto, no máximo cerca de duas vezes mais longa do que a maior largura da antera.

5. Sépalas e pétalas patentes 6. Phymatidium microphyllum

5'. Sépalas laterais e pétalas curvadas para frente

7. Phymatidium microphyllum var. herteri

3'. Aurículas da coluna distintamente papilosas.

6. Sépalas laterais e pétalas patentes

2. Phymatidium delicatulum

6'. Sépalas laterais e pétalas curvadas para cima

3. Phymatidium delicatulum var. curvisepalum

1. Phymatidium aquinoi Schltr., Repert. Spec. Nov. Regni Veg. Beih. 35: 101. $1925 . \quad$ Fig. 1a-c Planta 19-23 mm alt. Raízes glabras. Folhas 10-24 × 0,7-0,9 mm, unifaciais, cilíndricas a subtríquetras; ápice agudo. Inflorescência 52-95 mm compr., escapo glabro; brácteas $6-7 \times 0,5-1$ $\mathrm{mm}$. Flores com pedicelo obscuramente papiloso, ovário angular. Sépala dorsal 3,1-4 × 0,8-1 mm, oblongo-lanceolada ou ovado-lanceolada, patente, ápice agudo. Sépalas laterais $2,8-4 \times 0,8-1 \mathrm{~mm}$, oblongo-lanceoladas, onduladas, patentes, ápice agudo. Pétalas 3-4 × 0,9-1,1 mm, oblongolanceoladas, onduladas, patentes, ápice agudo; face adaxial com pequena calosidade central, elevada, situada na porção mediana. Labelo 3-5 $\times 1-1,5 \mathrm{~mm}$, inteiro, ovado-lanceolado, um pouco ondulado, ápice agudo; margens inteiras; disco com calosidade branca, ovado a arredondado, com o ápice verde, bidentado. Coluna 2-2,9 mm compr., fortemente sigmóide, minutamente auriculada na altura do rostelo, as aurículas triangulares quando explanadas, glabras; rostelo relativamente longo, deflexo; cavidade estigmática conspícua, ovada; desprovida de tabula infrasestigmática; antera prolongada em bico longo e agudo, bidentada próximo ao ápice; polinário com estipe caudadoespatulado, não bifurcado, obtuso na região de inserção das polínias, viscídio ovado.

Material selecionado examinado: Campina Grande do Sul, Jaguatirica, 22.I.1960, fl., G. Hatschbach 6674 (MBM). Carambeí, Catanduva de Fora, 4.I.2011, fl., M.E. Engels 230 (HUPG). Guaratuba, Colônia Limeira, 29.XII.1971, fl., G. Hatschbach 28593 (MBM). Ipiranga, 1.IX.1910, fl., P. Dusén 10183 (S). Morretes, Estrada 


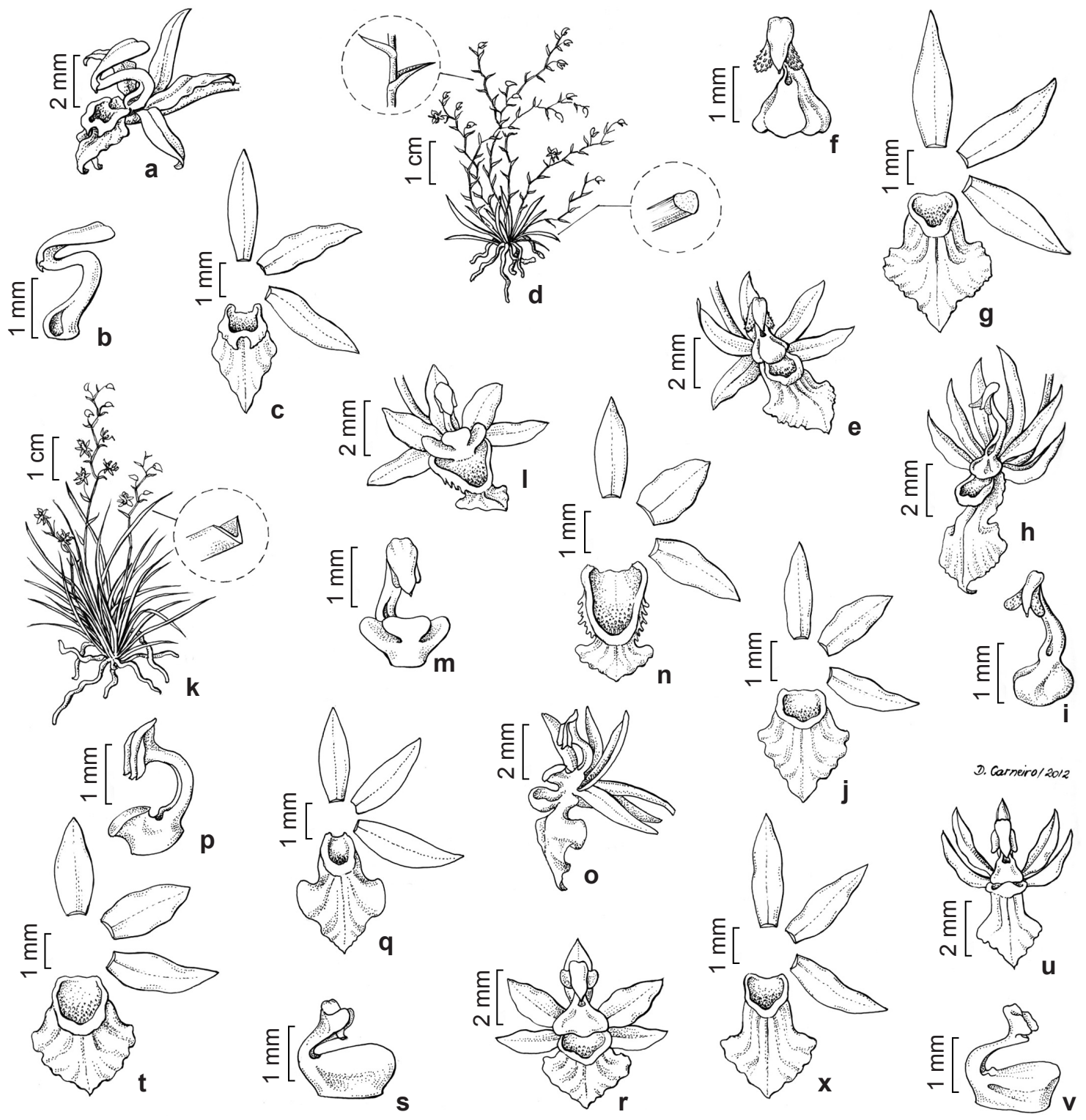

Figura 1 - a-c. P. aquinoi - a. flor, vista lateral; b. coluna, vista lateral; c. peças florais (J.M. Silva \& O.S. Ribas 6338). d-g. P. delicatulum - d. hábito, destacando a disposição das brácteas e a folha em secção transversal; e. flor, vista frontal; f. coluna, vista frontal; g. peças florais (C.A. Royer \& M. Bornschein 17). h-j. P. delicatulum var. curvisepalum - h. flor, vista lateral; i. coluna, vista lateral; j. peças florais (E.C. Smidt 1051). k-n. P. falcifolium k. hábito, destacando a folha em secção transversal; 1. flor, vista frontal; m. coluna, vista frontal; n. peças florais (E. Lopes 9). o-q. P. hysteranthum - o. flor, vista lateral; p. coluna, vista lateral; q. peças florais ( $V$. Ariati et al. 424). r-t. P. microphyllum - r. flor, vista frontal; s. coluna, vista lateral; t. peças florais (E.C. Smidt 1050). u-x. P. microphyllum var. herteri - u. flor, vista frontal; v. coluna, vista lateral; x. peças florais (G. Hatschbach et al. 13561). Figure 1 - a-c. P. aquinoi - a.flower, lateral view; b. columm, lateral view; c. floral parts (J.M. Silva \& O.S. Ribas 6338). d-g. P. delicatulum - d. habit, emphasizing the bracts arrangement and leaf in cross section; e. flower, front view; f. columm, front view; g. floral parts (C.A. Royer \& M. Bornschein 17). h-j. P. delicatulum var. curvisepalum - h. flower, lateral view; i. columm, lateral view; j. floral parts (E.C. Smidt 1051). k-n. P. falcifolium - k. habit, emphasizing the leaf in cross section; 1. flower, front view; m. columm, front view; n. floral parts (E. Lopes 9). o-q. P. hysteranthum - o. flower, lateral view; p. columm, lateral view; q- floral parts (V. Ariati et al. 424). r-t. P. microphyllum - r. flower, front view; s. columm, lateral view; t. floral parts (E.C. Smidt 1050). u-x. P. microphyllum var. herteri - u. flower, front view; v. columm, lateral view; x. floral parts (G. Hatschbach et al. 13561). 
da Graciosa, Rio Grota Funda, 5.II.2008, fl., J.M. Silva \& O.S. Ribas 6338 (MBM). Paranaguá, Pico Torto, 15.I.1970, fl., G. Hatschbach 23331 (MBM). São José dos Pinhais, Colônia Santos Andrade, 11.XII.1986, fl., J. Cordeiro \& G. Hatschbach 390 (MBM).

Phymatidium aquinoi é encontrada no Litoral, Serra do Mar, Primeiro e Segundo Planaltos habitando as Florestas Ombrófilas Densa e Mista e a Estepe Gramíneo Lenhosa (Fig. 2a). Ocorre também nos estados do Rio Grande do Sul, Santa Catarina, Rio de Janeiro, Minas Gerais e Espírito Santo (Toscano de Brito 2007).

Segundo os critérios da IUCN (2010), esta espécie se enquadra na categoria vulnerável (VU B2a), pois é registrada em menos de dez localidades no estado, nenhuma localizada em unidade de conservação. No estado do Espírito Santo é citada na lista de espécies ameaçadas como criticamente em perigo (Simonelli \& Fraga 2007).

Phymatidium aquinoi é facilmente reconhecida por suas sépalas e pétalas onduladas, pela coluna fortemente sigmóide e desprovida de tabula infraestigmática, e pela antera prolongada em bico longo e agudo. Floresce entre setembro e maio.

2. Phymatidium delicatulum Lindl., Gen. Sp. Orchid. Pl.: 210. 1833. = Phymatidium myrtophilum Barb. Rodr,. Gen. Sp. Orchid. Nov. 229. 1882. = Phymatidium paranaense A.Samp., Plant. Nov. vel min. cog. 59, t. 2.1916.

Fig. 1d-g

Planta 12-22 $\mathrm{mm}$ alt. Raízes glabras. Folhas 9-15 × 0,7-1 mm, unifaciais, cilíndricas a subtríquetras; ápice agudo. Inflorescência 30-54 mm compr., escapo glabro; brácteas 2,3-5 $\times 0,3-0,9 \mathrm{~mm}$. Flores com pedicelo papiloso, ovário angular. Sépala dorsal $2-3 \times 0,2-0,7 \mathrm{~mm}$, ovada, ovado-triangular ou oblongo-lanceolada, ereta, ápice agudo. Sépalas laterais 2,3-3 × 0,5-0,8 $\mathrm{mm}$, ovada a oblongo-lanceoladas, patentes, ápice agudo. Pétalas 2,1-2,9 × 0,8-1 mm, ovadolanceoladas a oblongo-lanceoladas, patentes, ápice agudo. Labelo 2,7-3,5 × 2,1-3 mm, levemente trilobado, largamente unguiculado, cordiforme
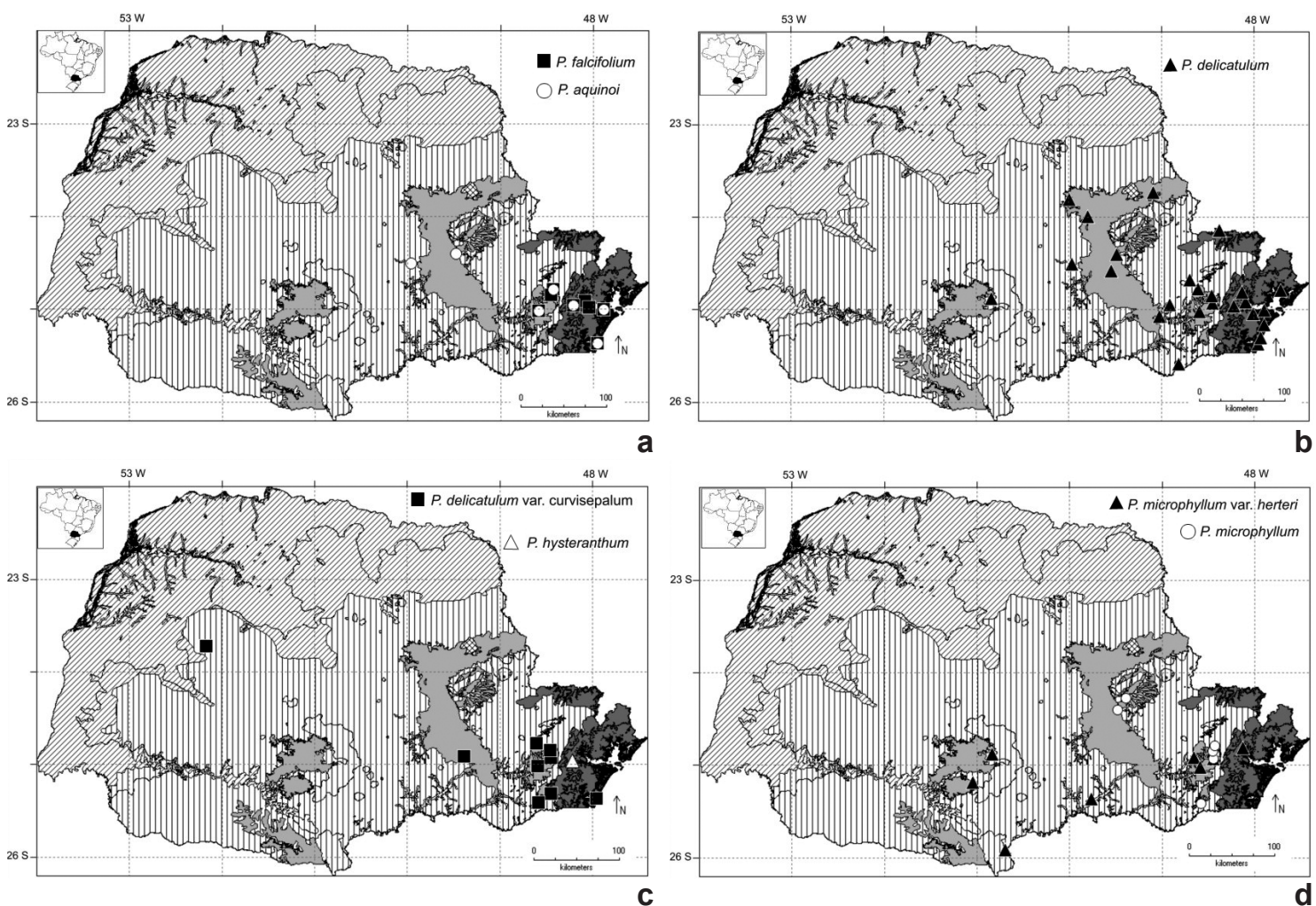

Figura 2 - Mapa de distribuição geográfica das espécies de Phymatidium no Paraná - a. P. aquinoi e P. falcifolium. b. $P$. delicatulum. c. P. delicatulum var. curvisepalum e P. hysteranthum. d. P. microphyllum e P. microphyllum var. herteri. Figure 2 - Distribution Map of Phymatidium species in Paraná - a. P. aquinoi and P. falcifolium. b. P. delicatulum. c. P. delicatulum var. curvisepalum and $P$. hysteranthum. d. P. microphyllum and $P$. microphyllum var. herteri. 
ou ovado-lanceolado; ápice agudo, margens irregulares, erosas, sobretudo na região mediana; disco provido de calosidade verde, subquadrada a ligulada. Coluna 1-2,1 mm compr., levemente arqueada a levemente sigmóide, auriculada na região apical, as aurículas ovadas quando explanadas, distintamente papilosas; rostelo curto, curvado para frente; cavidade estigmática pequena, ovada; tabula infraestigmática crassa, geralmente obovóide ou subglobosa; antera prolongada em bico curto, levemente emarginado e flanqueado por um par de dentes inconspícuos; polinário com estipe ovado-cuneado, não bifurcado, truncado na área de inserção das polínias, viscídio subelíptico. Material examinado: Sem localização precisa, s.d., fl., Lange 7894 (HB - coleta misturada com P. microphyllum); P. Dusén 13878 (S - coleta misturada com P. microphyllum var. herteri). Adrianópolis, Parque Estadual das Lauráceas, 11.I.2000, fl., F.G. Braga et al. (UPCB 42596). Alexandra, 24.III.1967, fl., H.M. Filho 398 (UPCB); 9.XI.1969, fl., Leinig 420 (HB). Antonina, 20.II.1965, fl., Saito 1249 \& Kuniyoshi 26 (HB); 27.II.1966, fl., G. Hatschbach 13911 (MBM, HB); Estrada Cacatu-Serra Negra, 18.II.1967, fl., G. Hatschbach 16011 (MBM); Reserva Biológica de Sapitanduva, 17.III.1993, fl., A.C. Cervi 4066 (UPCB); SPVS - Reserva do Rio Cachoeira, 29.I.2010, fl., M.E. Engels \& J.M.T. de Souza 154 (HUPG); SPVS - Reserva do Rio Cachoeira, 1.V.2012, fl., C.A. Royer 16 (UPCB). Balsa Nova, Serra Santa Ana, 13.XI.1969, fl., G. Hatschbach 23385 (MBM). Capão Grande, 25.I.1910, fl., P. Dusén 9245 (S). Carambeí, Catanduva de Fora, 11.XI.2009, fl., M.E. Engels 139 (HUPG); Alto Carambeí, 13.XII.2010, fl., M.E. Engels 234 (HUPG). Castro, Nascentes do Rio São José, 13.XII.2010, fl., M.E. Engels 235 (HUPG). Guarapuava, Águas, Santa Clara - Rio Jordão, 16.XI.1963, fl., Pereira 7935 (HB). Guaraqueçaba, Rio do Cedro, 30.I.1968, fl., G. Hatschbach 18516 (MBM, NY, HB); Rio do Costa, 9.II.1972, fl., G. Hatschbach 29134 (MBM); Salto Morato, 3.XII.1997, fl., A.C. Cervi \& O. Guimarães 6456 (UPCB); Reserva Natural Salto Morato, Trilha da Figueira, 2.XII.1998, fl., A.L.S. Gatti et al. 258 (UPCB); Parque Nacional do Superagui, 11.II.2013, fl., L.C.F. Rocha 107 (UPCB). Guaratuba, 31.I.1912, fl., P. Dusén 13600 (S); Rio da Divisa, 14.XII.1963, fl., G. Hatschbach 10865 (MBM); Pedra Branca de Araraquara, 30.XII.1965, fl., G. Hatschbach 13390 (UPCB); Rio da Praia, 31.XII.1966, fl., G. Hatschbach et al.15578 (MBM); II.2012, fl., C.A. Royer \& M. Bornschein 17 (UPCB). Jacareí, 12.II.1912, fl., P. Dusén 13870 (S, HB, NY, AMES); 21.II.1914, fl., P. Dusén 14452 (S, K, F, NY, AMES, MO). Jaguariaíva, Rio Samambaia, 18.XI.1970, fl., G. Hatschbach \& O. Guimarães 25465 (MBM). Ipiranga, 9.II.1904, fl., Dusén 3521 (R); 23.II.1911, fl., P. Dusén 11386 (S); 15.I.1914, fl., P. Dusén 14456 (S). Matinhos, Cabaraguara, 1.I.1988, fl., F. Straube 31 \& V.G. Persson 11 (MBM); Parque Estadual do Rio da Onça, 9.IV.2004, fl., J. Sonehara 28
(MBM). Morretes, Estrada para Barrerro, 18.II.1985, fl., A.O.S. Vieira (FUEL 429). Passa Sete, 12.II.1971, fl., Dombreowski 3257 \& Kuniyoshi 2635 (HB). Paranaguá, Morro Ai Jesus, 24.XI.1967, fl., G. Hatschbach 17963 (MBM); Tinguçu, 31.III.2008, fl., Bonaldir 339 (HUCP). Piên, Campina dos Crispim, 5.XII.1962, fl., G. Hatschbach 9543 (MBM, HB). Piraquara, Rio do Corvo, Picado Mãe Catira, 1.V.1949, fl., G. Hatschbach 1388 (MBM); Mananciais da Serra, III.2005, fl., M. Reginato 218 (UPCB). Pontal do Sul, XII.2009, fl., E.C. Smidt 961 (UPCB). Quatro Barras, Rio Capivari, 26.XI.1962, fl., G. Hatschbach 9486 (MBM). Rio Branco do Sul, Mato Bom, 2.XII.2006, fl., A. Dunaiski Jr 3251 (MBM). São José dos Pinhais, Chácara Poço Branco, 14.IX.2012, fl., L.C.F. Rocha et al. 74 (UPCB). Telêmaco Borba, Usina Hidrelétrica de Mauá, XI.2011, fl., V. Ariati 594 (UPCB). Terezina, 21.I.1911, fl., P. Dusén 11164 (S). Tibagi, Salto Santa Rosa, 4.XI.94, fl., Ana C.S.F. et al. 39 (FUEL); Floresta do Salto Santa Rosa, 27.X.1995, fl., A.R.S. Vaz et al. (FUEL 17424).

Phymatidium delicatulum é encontrado no Litoral, Serra do Mar, Primeiro e Segundo Planaltos habitando as Florestas Ombrófilas Densa e Mista e Estepe Gramíneo Lenhosa (Fig. 2b). Ocorre também nos estados do Rio Grande do Sul, Santa Catarina, São Paulo, Rio de Janeiro, Espírito Santo, Bahia e Pernambuco (Toscano de Brito 2007, Barros et al. 2013), alcançando também a Província de Misiones na Argentina (Johnson 2001).

Segundo os critérios da IUCN (2010), $P$. delicatulum deve ser enquadrada na categoria pouco preocupante (LC), pois é registrada em mais de dez localidades no estado. Em unidade de conservação é encontrada no Parque Nacional do Superagui, Parque Estadual das Lauráceas, Parque Estadual Rio da Onça, Reseva Biológica Sapitanduva, Reserva Natural do Salto Morato e SPVS-Reserva do Rio Cachoeira.

Phymatidium delicatulum é reconhecida através de suas sépalas e pétalas patentes mais ou menos lanceoladas, assim como pelas aurículas da coluna marcadamente papilosas. Floresce de setembro a maio.

\section{Phymatidium delicatulum var. curvisepalum} Toscano, Kew Bulletin 62: 537. 2007. Fig. 1h-j Planta 12-22 mm alt. Raízes glabras. Folhas 8,8-19 × 0,7-1 mm, unifaciais, cilíndricas a subtríquetras; ápice agudo. Inflorescência 25-123 mm compr., escapo glabro; brácteas 3,1-7 × 0,3-0,9 $\mathrm{mm}$. Flores com pedicelo papiloso, ovário angular. Sépala dorsal 2,5-2,9 × 0,5-0,9 mm, ovada, ovado-triangular ou oblongo-lanceolada, ereta, ápice agudo. Sépalas laterais $2-3 \times 0,5-0,9 \mathrm{~mm}$, 
ovada a oblongo-lanceoladas, curvadas para cima, ápice agudo. Pétalas 2,3-2,9 × 0,7-1 mm, ovadolanceoladas a oblongo-lanceoladas, curvadas para cima, ápice agudo. Labelo 3-3,8 × 2,5-3,5 mm, levemente trilobado, largamente unguiculado, cordiforme ou ovado-lanceolado; ápice agudo; margens irregulares, erosas, sobretudo na região mediana; disco provido de calosidade verde, subquadrada a ligulada. Coluna 1,8-2 mm compr., levemente arcada a levemente sigmóide, auriculada na região apical, as aurículas ovadas quando explanadas, distintamente papilosas; rostelo curto, curvado para frente; cavidade estigmática pequena, ovada; tabula infraestigmática crassa, geralmente obovóide ou subglobosa; antera prolongada em bico curto, levemente emarginado, flanqueado por um par de dentes inconspícuos; polinário com estipe ovado-cuneado, não bifurcado, truncado na área de inserção das polínias, viscídio subelíptico. Material examinado: Campina Grande do Sul, Campininha, 27.X.1946, fl., G. Hatschbach 509 (MBM). Colombo, Hotel Betânia, fl., P.R.P. Andrade (MBM 297891). Guaratuba, Rio da Praia, fl., Leinig 267 (HB). Palmeira, Fazenda Santa Rita, 13.X.1982, fl., G. Hatschbach 45646 (MBM). Piraquara, Campininha, 27.X.1946, fl., Hatschbach 509 (MBM, RB, PACA); Serra Piramirim, 1.X.1997, fl., J.M. Silva et al. 2019 (MBM); Parque dos Mananciais, 26.IX.2001, fl., R. Goldenberg 508 (UPCB); Mananciais da Serra, 5.X.2001, fl., R. Kersten 1240 (HUCP); Mananciais da Serra, 10.X.2003, fl., M.G. Caxambu 105 (MBM, HCF); Haras Santo Antonio, 6.XI.2003, fl., R. Kersten 714 (UPCB); Mananciais da Serra, X.2005, fl., M. Reginato 591 (UPCB); Mananciais de Piraquara, 14.X.2010, fl., M.E. Engels 237 (HUPG). Quatro Barras, Rio Taquari, 25.X.1979, fl., J.C.J. 1 (HUCP); 4.XI.1980, fl., G. Hatschbach 43272 (MBM); Colônia Japonesa, 31.X.1981, fl., R. Kummrow 1582 (MBM, SP). São José dos Pinhais, Barro Branco, 11.XI.1965, fl., G. Hatschbach 13133 (MBM, F, UPCB); Reserva Vossoroca, IX.2012, fl., E.C. Smidt 1051 (UPCB). Tijucas do Sul, Vossoroca, 15.X.1961, fl., G. Hatschbach 8448 (MBM); Lagoa - Lagoinha, 11.III.2000, fl., M. T. Shirata 4201 (HUCP).

Phymatidium delicatulum var. curvisepalum é encontrada no Litoral, Serra do Mar, Primeiro e Segundo Planaltos, alcançando o limite com o Terceiro Planalto, habitando as Florestas Ombrófilas Densa e Mista e Estepe Gramíneo Lenhosa (Fig. 2c). Ocorre também nos estados de Santa Catarina e São Paulo (Barros et al. 2013).

Segundo os critérios da IUCN (2010), esta variedade enquadra-se na categoria vulnerável (VU B2a), pois é registrada em menos de 10 localidades no estado, nenhuma localizada em unidade de conservação.
Phymatidium delicatulum var. curvisepalum difere da variedade típica pela inflorescência geralmente mais longa e, sobretudo, pelas sépalas laterais e pétalas marcadamente curvadas para cima. Floresce de setembro a março.

4. Phymatidium falcifolium Lindl., Gen. Sp. Orchid. Pl. 210. 1833. = Phymatidium tillandsioides Barb. Rodr. Gen. Sp. Orchid. Nov., 228. 1882.

Fig. 1k-n

Planta 37-48 mm alt. Raízes glabras. Folhas 27-34 × 0,7-1 mm, bifaciais, conduplicadas; ápice acuminado. Inflorescência 44-61 mm compr., escapo glabro, brácteas 2,1-3 × 0,5-0,7 mm. Flores com pedicelo glabro, ovário angular. Sépala dorsal 2-2,9 × 0,8-0,9 mm, oblongo-lanceolada ou elíptica, ereta; ápice agudo a obtuso. Sépalas laterais 2,3-2,8 × 0,8-1 mm, ovadas a oblongolanceoladas ou elípticas, patentes; ápice agudo a obtuso. Pétalas 2,5-3 × 1-1,1 mm, oblongas, ovadas ou ovado-lanceoladas, patentes; ápice agudo a obtuso. Labelo 1,8-2,9 × 1-2 mm, inteiro, oblongo, ovado ou obovado; ápice obtuso; margens eroso-laceradas na base e no meio e inteira no ápice, ondulada; disco provido de calosidade branca, ovada, cobrindo cerca de $3 / 4$ do labelo. Coluna 0,7-1 mm compr., levemente arqueada, desprovida de aurículas no ápice; rostelo curto, curvado para frente; cavidade estigmática pequena, ovado-lanceolada; tabula infraestigmática crassa, trilobada, a porção central verde brilhante, os lóbulos laterais mais claros, voltados para cima em forma de aurículas grandes intumescidas; antera prolongada em bico muito curto, sem dentes laterais próximo ao ápice emarginado; polinário com estipe cuneado, truncado na região de inserção das polínias, viscídio oblongo.

Material examinado: Antonina, Cachoeira, 15.I.1976, fl., G. Hatschbach 37949 (MBM); Usina Hidrelétrica Parigot de Souza, 10.I.1994, fl., G. Hatschbach \& E. Barbosa 59797 (MBM). Campina Grande do Sul, Serra da Igreja, Morro dos Padres, fl., A.Y. Mocochinski \& M.B. Scheer 206 (MBM). Guaratuba, Serra de Araraquara, Morro do Cauvi, 30.XII.1963, fl., G. Hatschbach 11060 (MBM, B); Rio Sai, 17.I.1970, fl., G. Hatschbach 23350 (MBM, C, HB, NY); Alto da Serra, Rio Itararé, 10.III.1996, fr., O.S. Ribas \& L.B.S. Pereira 1379 (MBM). Morretes, Serra da Prata, 25.II.1911, fl., P. Dusén 11788-A \& 1178 (S); Porto de Cima, 21.I.1914, fl., P. Dusén 14301 (AMES, S); Usina Elétrica Marumby, 4.I.1966, fl., G. Hatschbach et al. 13415 (MBM, HB, F); Rio Ipiranga, 4.I.1966, fl., G. Hatschbach 13447 (UPCB); Colônia Floresta, 24.I.1969, fl., G. Hatschbach \& C. Koczicki 20923 (MBM); Porto de Cima, 4.I.1975, fl., A. Dziewa 140 (MBM); Reserva 
Biológica Sapitanduva, 29.I.1985, fl., G.P. Lewis et al. 1401 (MBM); Porto de Cima - Rio Nhundiaquara, fl., I.2012, E. Lopes 9 (UPCB), Caminho de Itupava, 25.VII.2012, fr. M.E. Engels 413 (UPCB). Paranaguá, Picadão Cambará - Colônia Limeira, 14.II.1968, fl., G. Hatschbach 18606 (MBM); Tinguçu, 16.XII.2007, fl., Bonaldir 296 (HUCP). São José dos Pinhais, Castelhanos, 7.II.1998, fl., J.M. Silva et al. 2251 (MBM).

Material adicional examinado: BRASIL. BAHIA: Camacã, Fazenda Serra Bonita, RPPN Serra Bonita, 29.X.2004, fl., A.M. Amorim et al. 4350 (HUEFS); 29.X.2005, fl., A.M. Amorim et al.5415 (HUEFS).

Phymatidium falcifolium é encontrada no Litoral, Serra do Mar e Primeiro Planalto habitando as Florestas Ombrófilas Densa e Mista e Estepe Gramíneo Lenhosa (Fig. 2a). Ocorre também nos estados de Santa Catarina, São Paulo, Rio de Janeiro e Espírito Santo, alcançando também o Uruguai (Barros et al. 2013; Herter 1930). É aqui citada pela primeira vez para o estado da Bahia.

Segundo os critérios da IUCN (2010), a espécie enquadra-se na categoria vulnerável (VU $\mathrm{B} 2 \mathrm{a})$, pois é registrada em menos de 10 localidades no estado. Em unidade de conservação é encontrada na Reserva Biológica Sapitanduva. No estado do Espírito Santo é citada na lista de espécies ameaçadas como criticamente em perigo (Simonelli \& Fraga 2007).

Phymatidium falcifolium se distingue das demais espécies do gênero pelas folhas conduplicadas, longas e caudadas, distribuídas em espiral densa ao longo do caule relativamente alongado que lembram, em seu conjunto, pequenos espécimes de Tillandsia (Bromeliaceae). Floresce de dezembro a julho.

5. Phymatidium hysteranthum Barb. Rodr., Gen. Sp. Orchid. Nov.: 288. 1882.

Fig. 1o-q

Planta 11-20 $\mathrm{mm}$ alt. Raízes papilosas. Folhas 9-17 × 0,9-1 mm, unifaciais, cilíndricas a subtríquetras; ápice agudo. Inflorescência 43-63 mm compr., escapo glabro; brácteas 3-4,5 $\times 0,2-0,8 \mathrm{~mm}$. Flores com pedicelo obscuramente papiloso, ovário tricarenado. Sépala dorsal 3-3,2 $\times$ $1 \mathrm{~mm}$, ovada a lanceolada, patente; ápice agudo a obtuso. Sépalas laterais 3-3,2 × 0,8-1 mm, ovadas a oblongas, reflexas; ápice agudo a obtuso. Pétalas 3-3,3 × 0,9-1 mm, ovadas, oblongas ou lanceoladas, levemente reflexas e curvadas para cima; ápice agudo a obtuso. Labelo $3 \times 2,9-3 \mathrm{~mm}$, levemente trilobado, largo-unguiculado, cordiforme; ápice agudo; margens dentadas a erosas no meio e inteiras na base e no ápice; disco provido de calosidade largo-ligulada, verde com as margens verde-claras. Coluna 2-2,2 mm compr., fortemente arqueada, levemente sigmóide, auriculada na região apical, as aurículas semi-lunadas quando explanadas; obscuramente papilosas; rostelo curto, curvado para frente; cavidade estigmática pequena, ovada; tabula infraestigmática relativamente pequena, subglobosa; antera prolongada em bico longo e arqueado, bidentada próximo ao ápice recurvado e emarginado; polinário com estipe espatulado, obscuramente emarginado na região de inserção das polínias, viscídio ovado.

Material examinado: Morretes, Estrada da Graciosa, 4.IV.2010, fl., V. Ariati et al. 424 (HUCP); Pico Marumbi, 9.III.2013, fl., M.E. Engels et al. 666 (UPCB). São José dos Pinhais, RPPN Nhandara Guaricana, 1.VII.2013, fl., M.E. Engels \& L.C.F. Rocha 1405 (UPCB).

Phymatidium hysteranthum é encontrada na Serra do Mar e Primeiro Planalto habitando a Floresta Ombrófila Densa (Fig. 2c), até o momento conhecida apenas por três espécimes no Paraná. Ocorre também nos estados de São Paulo, Rio de Janeiro, Minas Gerais e Espírito Santo (Barros et al. 2013). Esta espécie encontrava-se previamente registrada para o Paraná por Pabst \& Dungs (1977), porém tal registro ocorreu sem a citação de um material testemunho. Após a análise de toda a coleção de Phymatidium depositada no Herbarium Bradeanum (HB), onde se encontra depositada a maior parte dos espécimes estudados por Guido Pabst, Toscano de Brito (2007) considerou que o registro de Pabst \& Dungs (1977) deva ter sido fruto de erro de identificação.

Segundo critérios da IUCN (2010), esta espécie deve ser enquadrada na categoria em perigo (CR B2a), pois é registrada em apenas duas localidades do estado. Em unidade de conservação é encontrada na RPPN Nhandara Guaricana.

Phymatidium hysteranthum é distinguida das demais espécies do gênero pelas sépalas laterais marcadamente reflexas, as pétalas um tanto eretas e curvadas, a antera prolongada em bico longo, provido no ápice de um par de dentes laterais inconspícuos, e a tabula infraestigmática pequena. Floresce entre março e julho.

6. Phymatidium microphyllum (Barb. Rodr.) Toscano, Lindleyana 16: 211. 2001. Fig. 1r-t Planta 7-10 mm alt. Raízes glabras ou papilosas. Folhas 5,5-8 × 0,9-1 mm, unifaciais, cilíndricas a subtríquetras; ápice agudo. Inflorescência 30-44 mm compr., escapo papiloso; brácteas 2,1-3,5 $\times$ 0,4-1,1 mm. Flores com pedicelo levemente 
papiloso, ovário obscuramente angular. Sépala dorsal 2-2,8 $\times 0,5-1 \mathrm{~mm}$, ovada a oblongo-lanceolada, patente; ápice agudo. Sépalas laterais 2-2,9 $\times$ 0,8-1 mm, ovadas a ovado-lanceoladas, patentes; ápice agudo. Pétalas 2,2-2,9 × 1-1,2 mm, ovadas a ovado-lanceoladas, patentes; ápice agudo. Labelo 2,5-3,2 × 2,3-2,9 mm, levemente trilobado, largounguiculado, obovado ou ovado-lanceolado; ápice agudo a obtuso; margens eroso-onduladas; disco provido de calosidade verde, com as margens externas mais escuras, ligulada. Coluna $1-1,5 \mathrm{~mm}$ compr., fortemente encurvada, auriculada na região apical, as aurículas mais ou menos semicirculares a ovadas quando explanadas, estendendo-se desde o ápice até mais ou menos a metade da coluna, glabras, raramente obscuramente papilosas; rostelo curto, curvado para cima; cavidade estigmática pequena, ovada; tabula infraestigmática crassa, obovada, igualando ou superando o comprimento da coluna; antera prolongada em bico curto, obtuso, levemente emarginado, provido lateralmente de um par de dentes inconspícuos; polinário com estipe cuneado, bifurcado na região de inserção das polínias, viscídio elíptico.

Material examinado: Sem localização precisa, 12.XII.1909, fl., Lange 7894 (HB - coleta misturada com P. delicatulum). Carambei, Catanduva de Fora, 11.XI.2009, fl., M.E. Engels 139 (HUPG). Castro, Nascentes do Rio São José, 13.XII.2010, fl., M.E. Engels 235 (HUPG). Quatro Barras, Serrinha, 9.XII.1908, fl., P. Dusén p.p. 733 (S); Borda do Campo, 4.I.1974, fl., G. Hatschbach 33631 (MBM, HB); Taquari, 29.I.1975, fl., L.F. Ferreira 198 (MBM, HB). Piraquara, Serra Piramirim, 15.XII.1995, fl., J.M. Silva \& J.M. Cruz 1595 (MBM, UPCB, FUEL). Tijucas do Sul, Saltinho, 28.XII.1958, f1., G. Hatschbach 5396 (MBM, HB); Matulão, 1.I.1964, fl., G. Hatschbach 10871 (MBM, HB, B, UPCB); XII.2011, fl., E.C. Smidt 1050 (UPCB).

Phymatidium microphyllum é encontrada no Primeiro e Segundo Planaltos habitando as Florestas Ombrófilas Densa e Mista (Fig. 2d). Ocorre também nos estados do Rio Grande do Sul, Santa Catarina e Minas Gerais (Barros et al. 2013).

Segundo os critérios da IUCN (2010), a espécie é considerada vulnerável (VU B2a), pois é registrada em menos de 10 localidades no estado, nenhuma localizada em unidade de conservação.

Phymatidium microphyllum assemelha-se a P. delicatulum, porém difere dessa, principalmente pela forma da coluna, especialmente pelas aurículas maiores, glabras ou apenas obscuramente papilosas, e pelo estipe bifurcado na região de inserção das polínias. A tabula infraestigmática também é maior e mais intumescida que em P. delicatulum. Floresce de novembro a janeiro.
7. Phymatidium microphyllum var. herteri (Schltr.) Toscano, Lindleyana 16: 211. 2001 . Fig. 1u-x Planta 16-37 mm alt. Raízes glabras. Folhas $13-27 \times 0,9-1 \mathrm{~mm}$, unifaciais, cilíndricas a subtríquetras; ápice agudo. Inflorescência 45-91 mm compr., escapo papiloso; brácteas 5-8,2 × 0,4-0,7 $\mathrm{mm}$. Flores com pedicelo levemente papiloso, ovário obscuramente angular. Sépala dorsal 2,1-4 $\times 0,9-1 \mathrm{~mm}$, ovada a oblongo-lanceolada, voltada para frente; ápice agudo. Sépalas laterais 2-3,9 × $0,8-1 \mathrm{~mm}$, ovadas a ovado-lanceoladas, voltadas para frente; ápice agudo. Pétalas 2,1-3,8 × 0,9-1 $\mathrm{mm}$, ovadas a ovado-lanceoladas, voltadas para frente; ápice agudo. Labelo 3-4,8 × 2-3,2 mm, largo-unguiculado, obovado, cordiforme; ápice agudo a obtuso; margens eroso-onduladas; disco provido de calosidade verde, com as margens externas mais escuras, ligulada. Coluna 1-1,8 $\mathrm{mm}$ compr., fortemente encurvada, auriculada na região apical, as aurículas subquadradas quando explanadas, geralmente quase perpendiculares ao eixo da coluna, glabras; rostelo curto, curvado para cima; cavidade estigmática pequena, ovada; tabula infraestigmática crassa, obovada, igualando ou superando o comprimento da coluna; antera prolongada em bico curto, obtuso, levemente emarginado, provido lateralmente de um par de dentes inconspícuos; polinário com estipe levemente bifurcado, bilobado a subtruncado na região de inserção das polínias, viscídio elíptico.

Material examinado: Antonina, Estrada Cacatu-Serra Negra, 19.I.1966, fl., G. Hatschbach et al. 13561 (MBM). Curitiba, 2.III.1912, fl., P. Dusén 13878 (S). General Carneiro, Rio Lageado, 12.II.1966, fl., G. Hatschbach et al. 13856 (MBM, HB). Guarapuava, Cachoeira dos Turcos, 13.II.1969, fl. e fr., G. Hatschbach 21177 (MBM, HB). Pinhão, Rio São Jerônimo, 20.III.2003, fl., R. Kersten 611 (UPCB). Piraquara, Estrada da Graciosa, Alto da Serra, 22.IV.1951, fl., $G$. Hatschbach 2245 (MBM, SP); Novo Tirol, 3.II.1967, fl., G. Hatschbach 16093 (MBM). Quatro Barras, Rio do Corvo, 1.IV.1969, fl., G. Hatschbach 21304 (MBM); Morro Sete, 27.III.1990, fl., A.C. Cervi \& O.S. Ribas 3064 (MBM). São José dos Pinhais, Colônia Roseira, 23.II.1968, fl., C. Koczicki 81 (MBM, HB). São Mateus, fl., Gurgel - Instituto de Quimica 14641 (RB).

Phymatidium microphyllum var. herteri é encontrada na Serra do Mar, Primeiro e Segundo Planaltos habitando as Florestas Ombrófilas Densa e Mista e a Estepe Gramíneo Lenhosa (Fig. 2d). Ocorre também nos estados do Rio Grande do Sul e Santa Catarina (Barros et al. 2013).

Segundo os critérios da IUCN (2010), a variedade é considerada vulnerável (VU B2a), pois 
é registrada em menos de 10 localidades no estado, nenhuma localizada em unidade de conservação.

Phymatidium microphyllum var. herteri difere da variedade típica pelas peças florais mais lanceoladas, além das sépalas e pétalas curvadas para frente, conferindo às flores uma aparência algo que fechada, e pelas aurículas subquadradas da coluna. Floresce de janeiro a abril.

\section{Agradecimentos}

Os autores agradecem aos curadores dos herbários o empréstimo dos materiais, e a Diana Carneiro a confecção das ilustrações. À CAPESPNADB (17/2009 - Proposta botânica UFPR/IBT/ Unicamp) a bolsa de mestrado concedida, ao IAP $\left(\mathrm{N}^{\circ} 326 / 11\right)$ e ao ICMBio (SISBIO - 30642-1) as autorizações de coletas. Agradecemos também as sugestões dos dois revisores por tornarem o texto mais claro e padronizado.

\section{Referências}

APG III. 2009. An update of the Angiosperm Phylogeny Group classification for the orders and families of flowering plants: APG III. Botanical Journal of the Linnean Society 161: 105-121.

Barbosa Rodrigues, J. 1882. Genera et Species Orchidearum Novarum. Vol. 2. Tipografia Nacional. Rio de Janeiro.

Barros, F.; Vinhos, F.; Rodrigues, V.T.; Barberena, F.F.V.A.; Fraga, C.N. \& Pessoa, E.M. 2013. Orchidaceae. In: Lista de espécies da flora do Brasil. Jardim Botânico do Rio de Janeiro. Disponível em: $<$ http://floradobrasil. jbrj.gov.br/2012/FB011990>. Acesso em 22 Jan 2013.

Brummitt, R.K. \& Powell, C.E. 1992. Authors of plants names. Royal Botanic Gardens, Kew. 732p.

Chase, M.W.; Freudenstein, J.V.; Cameron, K.M. \& Barrett, R.L. 2003. DNA data and Orchidaceae systematics: a new phylogenetic classification. In: Dixon, K.W.; Kell, S.P.; Barrett, R.L. \& Cribb, P.J. Orchid conservation. Natural History Publications, Kota Kinabalu. Pp. 69-89.

Cogniaux, A. 1904-1906. Orchidaceae. In: Martius, C.F.P.; Eichler, A.G. \& Urban, I. Flora brasiliensis. Vol. 3, Part 6. Typographia Regia, Munachii. 604p.

Dallwitz, M.J.; Paine, T.A. \& Zurcher, E.J. 2011. DELTA Editor: description language for taxonomy. Disponível em $<$ http://delta-intkey.com $>$. Acesso em 17 Set 2012.

Dressler, R.L. 2005. How many orchid species? Selbyana 26: $155-158$
Gonçalves, E.G. \& Lorenzi, H. 2011. Morfologia vegetal: organografia e dicionário ilustrado de morfologia das plantas vasculares. $2^{\text {a }}$ ed. Instituto Plantarum de Estudos da Flora, Nova Odessa. 512p.

Harris, J.G. \& Harris, M.W. 1994. Plant identification terminology: an illustrated glossary. Spring Lake Publishing, Spring Lake. 206p.

Hatschbach, G.G. \& Ziller, S.R. 1995. Lista vermelha de plantas ameaçadas de extinção no estado do Paraná. SEMA/GTZ, Curitiba. 139p.

Herter, W.G. 1930. Estudios botánicos de la región uruguaya IV, Florula Uruguayensis. Plantae Vasculares. Orchidaceae. Pp. 51-52.

Hijmans, R.J.; Guarino, L.; Bussink, C.; Mathur, P.; Cruz, M.; Barrentes, I. \& Rojas, E. 2012. DIVA-GIS: A geographic information system for the analysis of species distribution data. Versão 7.5. Disponível em $<$ http://www.diva-gis.org>. Acesso em 8 Out 2012.

IUCN Standards and Petitions Subcommittee. 2010. Guidelines for Using the IUCN Red List Categories and Criteria. Version 8.1. Preparedby the Standards and Petitions Subcommittee in March 2010. Disponível em $<$ http://intranet.iucn.org/webfiles/doc/SSC/RedList/ RedListGuidelines.pdf $>$. Acesso em 10 Out 2012.

Johnson, A.E. 2001. Las Orquídeas del Parque Nacional Iguazú. L.O.L.A., Buenos Aires. 296p.

Maack R. 1968. As zonas das paisagens naturais. In: Maack, R. Geografia física do Paraná. BADEP, UFPR, Curitiba. 526p.

Pabst, G.F.J. \& Dungs, F. 1977. Orchidaceae Brasilienses. Vol. 2. Brucke-Verlag Kurt Schmersow, Hildesheim. $418 \mathrm{p}$.

Simonelli, M. \& Fraga, C.N. 2007. Espécies da flora ameaçadas de extinção no estado do Espírito Santo. IPEMA, Vitória. 146p.

Stern, W.T. 2004. Botanical latin. Timber Press, Portland. $546 \mathrm{p}$.

Thiers, B. [continuously updated]. Index Herbariorum. Part I: The herbaria of the world. New York Botanical Garden. Disponível em $<$ http://sweetgum. nybg.org/ih/>. Acesso em 10 Ago 2012.

Toscano de Brito, A.L.V. 2001. Systematic Review of the Ornithocephalus group (Oncidiinae; Orchidaceae) with comments on Hofmeisterella. Lindleyana 16: 157-217.

Toscano de Brito, A.L.V. 2007. A taxonomic revision of the genus Phymatidium (Orchidaceae: Oncidiinae). Kew Bulletin 62: 529-560.

Veloso, H.P.; Rangel Filho, A.L.R. \& Lima, J.C.A. 1991. Classificação da vegetação brasileira adaptada a um sistema universal. IBGE/Projeto Radambrasil, Rio de Janeiro. 123p. 